\title{
Morphologic features of atrioventricular septal defect with only ventricular component: Further observations pertinent to surgical repair
}

\author{
Iki Adachi, MD, ${ }^{\text {a }}$ Hideki Uemura, MD, FRCS, ${ }^{\mathrm{b}}$ Karen P. McCarthy, BS, ${ }^{\mathrm{a}}$ and Siew Yen Ho, PhD, FRCPath, FESC
}

\begin{abstract}
Objective: Atrioventricular septal defect with only a ventricular component of septal deficiency is the least common of the various forms of this malformation. We reviewed its morphology in heart specimens and compared our findings with the other forms for a better understanding of its surgical morphology.
\end{abstract}

\begin{abstract}
Methods: We examined 78 cardiac specimens with atrioventricular septal defect; 56 (72\%) had common atrioventricular valve orifice with both atrial and ventricular components (so-called "complete" form), and 22 (28\%) had separate valve orifices (so-called "partial" or "incomplete" form) with 17 having only an atrial component (so-called "ostium primum" form) and 5 having only a ventricular component.
\end{abstract}

Results: Among hearts with atrioventricular septal defect, the hearts with only ventricular component of the defect had the mildest deformity of the ventricular mass, characterized by less inlet-outlet disproportion, smaller "gap" between anterior and posterior parts of the atrioventricular junction, and the least extensive septal deficiency. However, these hearts still possessed the characteristic common atrioventricular junction and had 5-leaflet configuration of the atrioventricular valve with similar proportions of mural leaflets in both valve orifices, as in other forms. Furthermore, owing to the unique relationship of the bridging leaflets to the septum, the leaflets were always "upwardly" displaced as opposed to "downwardly" displaced leaflets in "ostium primum" form.

Conclusions: Our observations suggest this entity might represent the mildest end of the whole spectrum of hearts with atrioventricular septal defect. Since "upwardly" displaced leaflets are not modifiable and could be aggravated further after surgery, they might play a role in late valve dysfunction.

Supplemental material is available online.

Becker and Anderson ${ }^{1}$ have described in their article on atrioventricular septal defect (AVSD) that "if the valve leaflets are removed, there is no way of distinguishing the variants of this group from one another.', Their contention is based on the observation that all the hearts with the stigmata of AVSD have comparable features in the ventricular mass and a common atrioventricular junction. This anatomic concept is particularly useful when differentiating hearts with true AVSD from superficially similar anomalies like cleft mitral valve. ${ }^{1,2}$ Despite these unifying features, it has been

From the Cardiac Morphology Unit, Imperial College London, National Heart \& Lung Institute, ${ }^{a}$ Department of Cardio-Thoracic Surgery, Royal Brompton and Harefield NHS Trust, ${ }^{b}$ London, United Kingdom.

This study is supported by the Francis Fontan prize of the European Association of Cardio-Thoracic Surgery awarded to Iki Adachi and a grant from The Uehara Memorial Foundation. The Cardiac Morphology Unit receives funding from the Royal Brompton and Harefield Hospital Charitable Fund.

Received for publication Jan 8, 2008; revisions received Feb 19, 2008; accepted for publication March 24, 2008.

Address for reprints: S. Yen Ho, PhD, FRCPath, FESC, Reader in Cardiac Morphology/Honorary Consultant, National Heart \& Lung Institute, Imperial College London, Guy Scadding Building, DoveHouse St, London SW3 6LY, United Kingdom (E-mail: yen.ho@imperial.ac.uk).

J Thorac Cardiovasc Surg 2009;137:132-8

$0022-5223 / \$ 36.00$

Copyright (c) 2009 by The American Association for Thoracic Surgery doi:10.1016/j.jtcvs.2008.03.032 shown that the degree of cardiac deformity varies considerably in the spectrum of hearts with AVSD and is associated with the anatomic status of valvular orifice and levels of intracardiac shunting. ${ }^{2,3}$

AVSD with only interventricular shunting is the rarest form of AVSD and is characterized by absence of an ostium primum defect. ${ }^{4,5}$ In contrast to the other widely investigated and well-compared types, namely, so-called "partial" (" incomplete" or "ostium primum") or "complete" AVSDs, this entity has gained very little attention from either surgeons or morphologists. In fact, the subset was not specified even in the large series of morphologic investigations of AVSD. ${ }^{2,3}$ This is probably due to its rarity. The rarity, however, might be explained, at least partially, by previous diagnostic confusion, ${ }^{6-10}$ and its true prevalence could be higher. Inasmuch as this potentially hidden form of AVSD requires special considerations when determining an approach to surgical correction, ${ }^{11,12}$ it is of critical importance to understand its unique anatomic features. The principal purpose of this study is to investigate the morphology of such hearts with special emphasis on how they are different from other forms of AVSD.

\section{MATERIALS AND METHODS}

This study has been approved by the Ethics Committee of the Royal Brompton Hospital, London, United Kingdom. From the cardiac specimen archive of the Royal Brompton Hospital, we identified 86 hearts with AVSD in the setting of usual atrial arrangement. Of these, 78 specimens were suitable for this morphologic examination, with 56 (72\%) having common 


\section{Abbreviations and acronyms \\ AVSD $=$ atrioventricular septal defect \\ $\mathrm{VSD}=$ ventricular septal defect}

atrioventricular valve orifice with potential intracardiac shunting at both the atrial and ventricular levels and $22(28 \%)$ having separate right and left valvular orifices. Of the latter, 17 had the bridging leaflets and connecting tissues firmly attached to the crest of the ventricular septum, resulting in all shunting through the defect being at only the atrial level (so-called ostium primum defect). In the remaining 5, the bridging leaflets were attached to the underside of the atrial septum, with possible shunting only at the ventricular level other than for any shunting across coexisting atrial communications such as an oval fossa defect.

Following the methods previously described by Penkoske, ${ }^{2}$ Ebels, ${ }^{3}$ and their associates, we measured ventricular septal lengths taken from the apex of the heart to three landmarks on its left ventricular aspect: the crux of the heart (for "inlet" length), the maximum excavated part of the ventricular component of the atrioventricular defect (for "minimal" length), and the attachment of the leaflet of the aortic valve (for "outlet" length) (Figure 1). We used this "outlet" length to standardize "inlet" and "minimal" lengths for each heart. Because the size of the hearts varied markedly within the series, standardization allowed us to make direct comparisons of these lengths. We also measured the size of the AVSD (Figure 1). "Atrioventricular junction" length was defined as the length of a straight line joining the anterosuperior and posteroinferior points of the anatomic atrioventricular junction across the septal defect (Figure 1). Distances of the deepest portions of either ventricular or atrial components from the atrioventricular junction line were measured, yielding a "scoop" length for the ventricular component and a "counter-scoop" length for the atrial component. The ventricular component was examined to determine whether it extended superiorly beyond the level of the inferior attachment of the aortic leaflets. If the "superior extension" was present, its length was measured (Figure 1). Scoop and counterscoop lengths were divided by inlet length, and superior extension length was divided by atrioventricular junction length for expression as a ratio.

We measured the annular circumferential attachments of leaflets in the atrioventricular valve orifices. In the left-sided atrioventricular valve, the annular circumferential attachment of the mural leaflet was measured as well as those of the left components of the superior and inferior bridging leaflets. Then, the proportion of the left mural leaflet in the left ventricular annulus was calculated. This was done in two ways ${ }^{2}$; the difference of the two methods was whether or not to include the septal length. In the right-sided valve, the annular circumferential attachments of the mural and anterosuperior leaflets were measured as well as the right component of the both bridging leaflets. As in the left-sided valve, proportions of these leaflets were calculated in two ways. In hearts with shunting only at the atrial or ventricular level in which the bridging leaflets were firmly attached to the septal structures, angles of the bridging leaflets in relation to the anatomic atrioventricular junction were determined (Figure 1). The axes of the bridging leaflets were defined by a line connecting the basal attachment of the leaflets onto the atrioventricular junction and a point where the edge of leaflets met the septal structure. If these axes were directed toward the ventricular side, positive values were given and vice versa.

The number and arrangement of the papillary muscles in the left ventricle were examined.

\section{RESULTS}

\section{Length of the Septal Surface}

Of all the 78 hearts, measurements of septal surface length were possible in $55(71 \%)$ hearts. The results are shown in Figure 2 and Table E1. In hearts with only a ventricular component, inlet ratios (inlet length/outlet length) were always more than $80 \%$ and clearly larger than those of other two forms. There was a tendency toward smaller ratios in hearts with both components than in those with only an atrial component, although a considerable overlap was observed between the two groups.

These tendencies were also the case in minimal ratios (minimal length/outlet length). Again, hearts with only a ventricular component have the largest value. Hearts with both components have smaller ratios than those with only an atrial component.

\section{Length of the AVSD}

Measurements of the size of the AVSD were possible in $53(68 \%)$ of the 78 hearts. The results are shown in Figure 2 and Table E1. Hearts with only a ventricular component had the smallest scoop ratios (scoop length/inlet length), whereas those with both components had the largest. Hearts with only an atrial component showed intermediate ratios between the other two forms. Similarly, hearts with only a ventricular component had the smallest counter-scoop ratios (counter-scoop length/inlet length), all being less than $10 \%$. Hearts with both components and only an atrial component had almost the same counter-scoop ratios. The superior extension of the defect was not observed in hearts with only a ventricular component or in those having only an atrial component, whereas it was frequently (21/42 hearts, $50 \%$ ) found in hearts with both components. A median value of superior extension ratio (superior extension length/atrioventricular junction length) in these hearts was $19 \%$ (range $7 \%-26 \%$ ).

There were differences in atrioventricular junction ratios (atrioventricular junction length/inlet length) among the three forms. Hearts with only a ventricular component showed the smallest values, whereas those with both components had the largest. Hearts with only an atrial component had intermediate values compared with the other two. When the atrioventricular junction lengths were plotted against outlet lengths, there was a linear correlation between the two lengths (Figure 3).

\section{Valvular Leaflet Arrangement}

Measurement of annular circumferential attachments of the valvular leaflets was possible in $44(56 \%)$ of the 78 hearts. The results are shown in Figure 4 and Table E2. Proportions of the mural leaflet in the left atrioventricular valve orifice in hearts with only a ventricular component were almost identical to those of the other two forms, irrespective of the inclusion of the septal length. Similarly, proportions of the mural leaflet in the right atrioventricular valve orifice in hearts with only a ventricular component were also almost identical to those of the other two forms. The proportions of the right mural leaflet were very similar to those of its counterpart on the left side, with approximately $30 \%$ without 

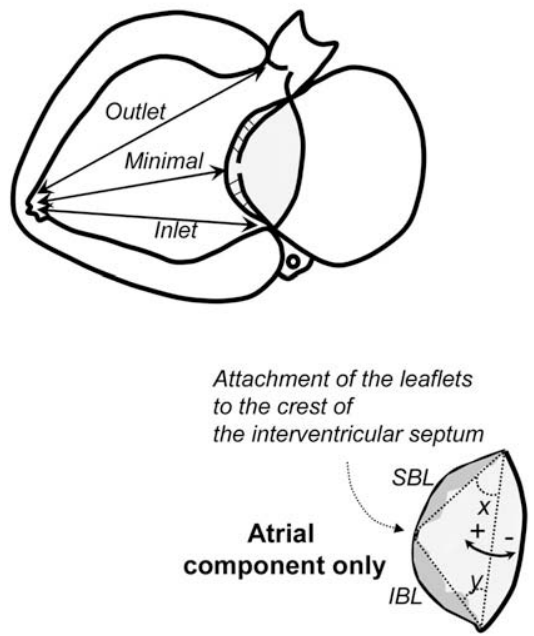
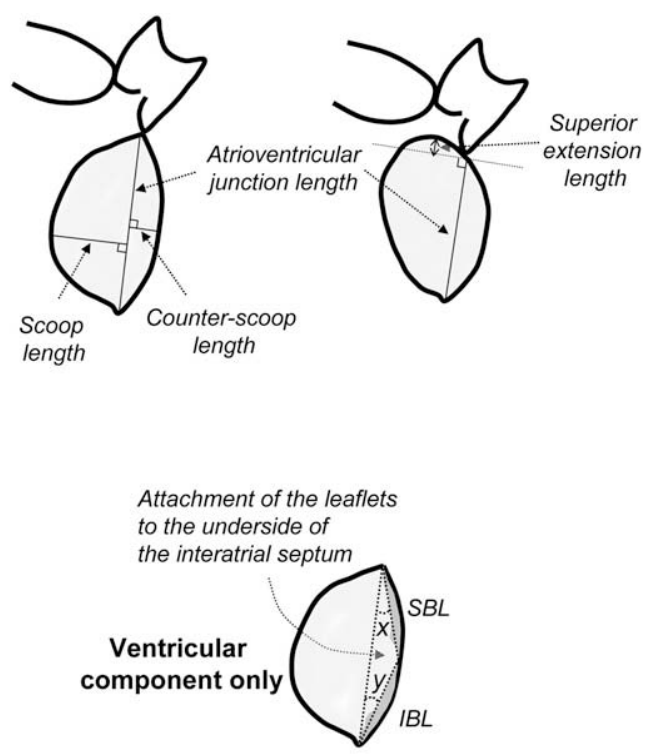

FIGURE 1. Left upper, Diagram showing the measurements made on the left ventricular aspect to determine the inlet, minimal, and outlet lengths. Middle and right upper, Diagrams showing the measurements made on the atrioventricular defect to determine the atrioventricular defect, scoop, counter-scoop and (if present) superior extension lengths. Lower, Diagrams showing angles of the bridging leaflets axis in relation to the atrioventricular junction (the chord $x$ for SBL and $y$ for IBL) are shown. If the axis is directed toward the ventricular side, a positive value is given and vice versa. $S B L$, Superior bridging leaflet; $I B L$, inferior bridging leaflet.

inclusion of the septal length and $20 \%$ with inclusion. In contrast, proportions of the anterosuperior leaflet were variable compared with those of the mural leaflets and were not identical among the three forms; hearts with only a ventricular component had the smallest value, whereas those with only an atrial component had the largest, with hearts having both components yielding highly diverse values. Conversely, hearts with only a ventricular component had a larger proportion of the right ventricular component of the superior bridging leaflet than those of hearts with only an atrial component. Again, hearts with both components showed highly variable proportions of the right ventricular component of the superior bridging leaflet.

\section{Angle of the Bridging Leaflets in Relation to the Anatomic Atrioventricular Junction}

Of all the 22 hearts with shunting either at only the ventricular or atrial level, the angles of the superior and inferior bridging leaflets in relation to the anatomic atrioventricular junction were determined in $12(55 \%)$ (Figure 1). The
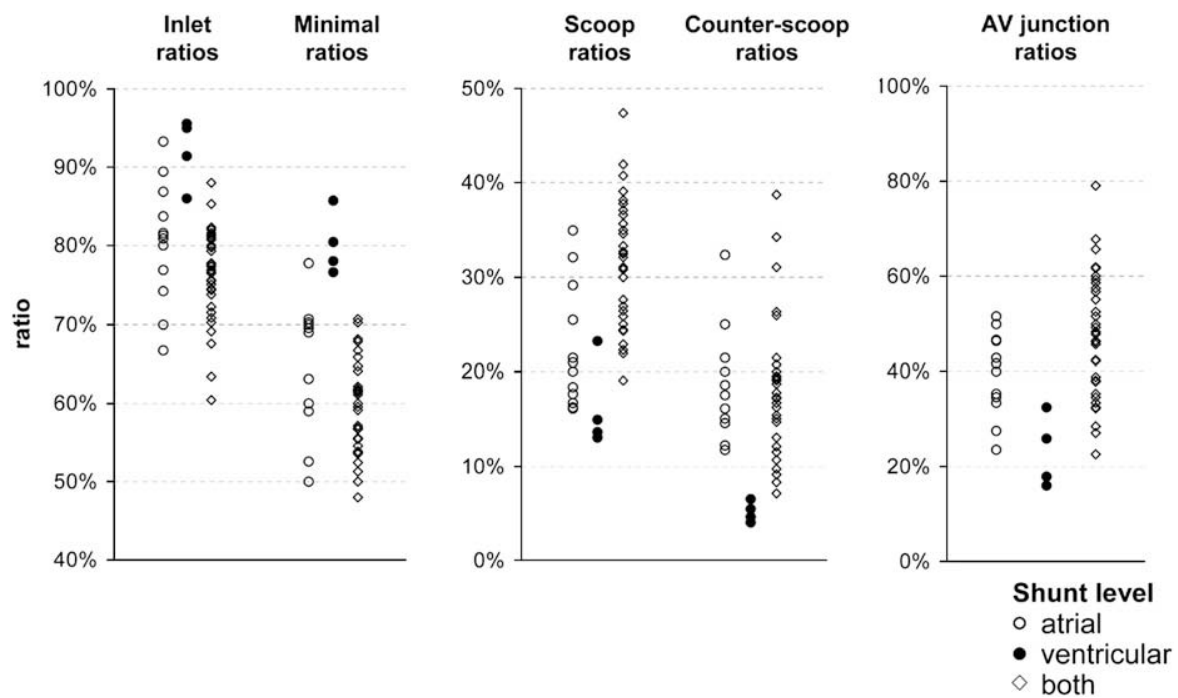

FIGURE 2. Results of our measurements on the left ventricular aspect of the septum and the atrioventricular septal defect. $A V$, Atrioventricular. 


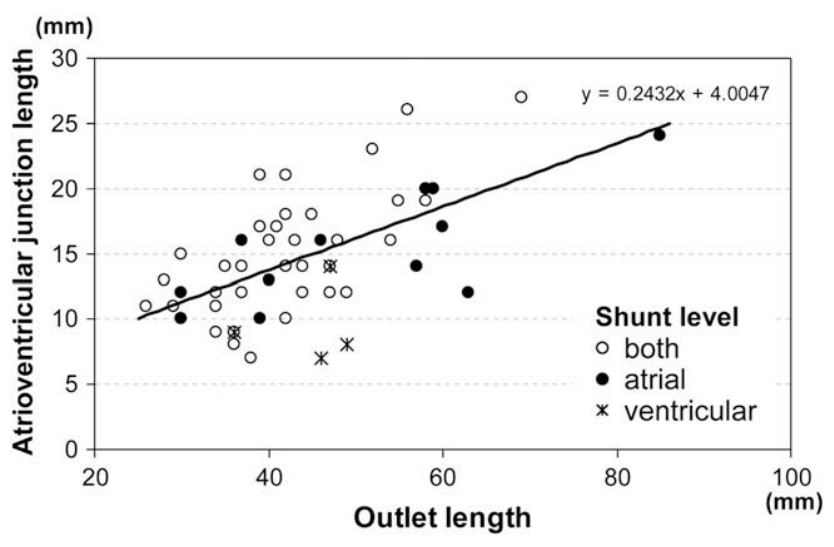

FIGURE 3. Relation between atrioventricular junction and outlet lengths. Linear relationship was found between the two lengths.

results are shown in Figure 5 and Table E2. In hearts with only a ventricular component $(n=5)$, the axes of both bridging leaflets were always directed toward the atrial side, yielding negative values. This result was in marked contrast to hearts with only an atrial component $(n=7)$; the axes of the leaflets were always directed toward the ventricular side, resulting in positive values.

\section{Papillary Muscles of the Left Ventricle}

Of the 78 hearts, the number and arrangement of papillary muscles in the left ventricle could be examined in $66(85 \%)$. In all hearts with either only a ventricular or an atrial component, there were always two papillary muscles with anteroposterior relationship. In contrast, abnormality in the number of papillary muscles was observed in $27 \%$ of those with both components; single muscle in $3(6 \%), 3$ muscles in $8(16 \%)$, and 5 muscles in $1(2 \%)$. In addition, abnormality in the arrangement of the papillary muscles was found in hearts with both components; 2 (4\%) specimens had obliquely positioned papillary muscles, and the remaining majority had the usual anteroposterior relationship.

\section{DISCUSSION}

AVSDs are usually grouped according to the anatomic status of the atrioventricular orifice, either being essentially common to both ventricles or being divided by connecting leaflet tissue between the facing bridging leaflets. ${ }^{1,13}$ From a surgical point of view, however, a crucial distinction is the level of intracardiac shunting through the defect. ${ }^{14}$ In this regard, three distinct patterns can exist: shunting at only the atrial level (partial AVSD with separate valvular orifices-so-called ostium primum defect), at both the atrial and ventricular levels (complete AVSD with a common valve orifice), and at only the ventricular level. Despite the presence of unifying features of these variants, ${ }^{1,13}$ the degree of cardiac deformity varies considerably among hearts with this anomaly; measurements of large series ${ }^{2,3}$ showed a significantly deeper scoop of a ventricular component and marginally greater inlet/outlet disproportion in complete AVSD than in partial AVSD. In contrast to these widely investigated and, more important, well-compared forms of AVSD, the third subset has gained much less attention in view of comparison with other types. Instead, the argument on this entity has always been focused on differentiation from hearts without the stigmata of AVSD, such as cleft mitral valve. ${ }^{7-10}$ Therefore, it is still unclear where this minor entity is positioned within the spectrum of AVSD.

Our measurements of septal surface length showed that hearts with only a ventricular component in our series had the mildest deformity of ventricular mass with the least extensive defect of the atrioventricular septum compared with other types. Hearts with only a ventricular component had much larger and nearly normal inlet ratios, all being
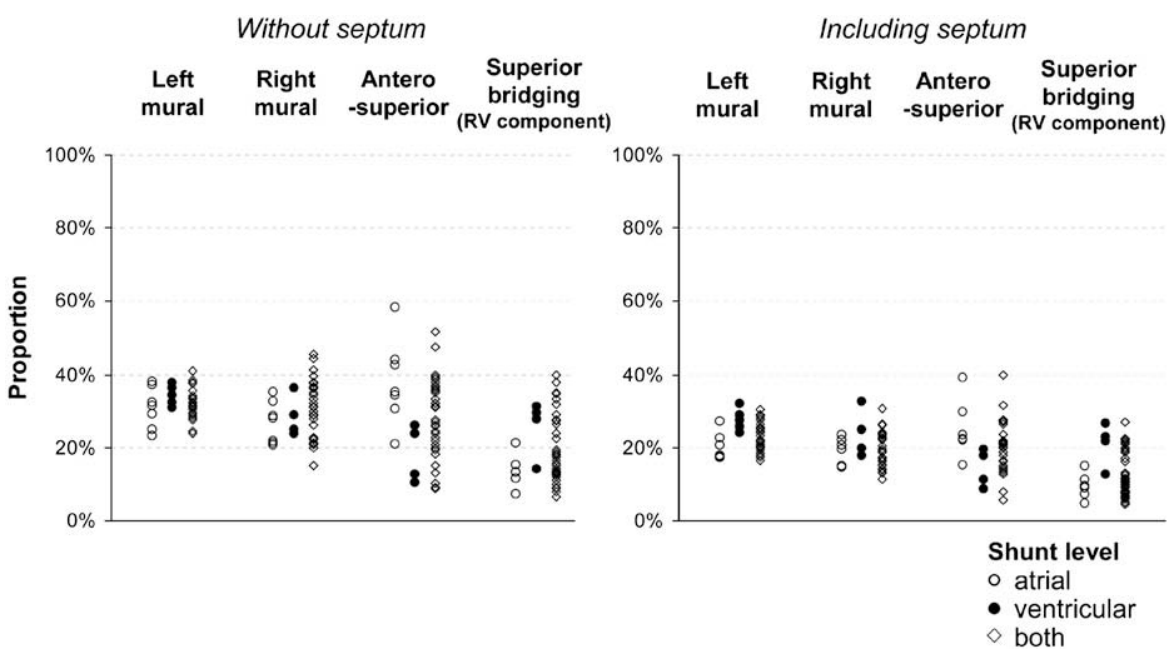

FIGURE 4. Annular circumferential attachment of valve leaflets with or without inclusion of the septal length. $R V$, Right ventricle. 


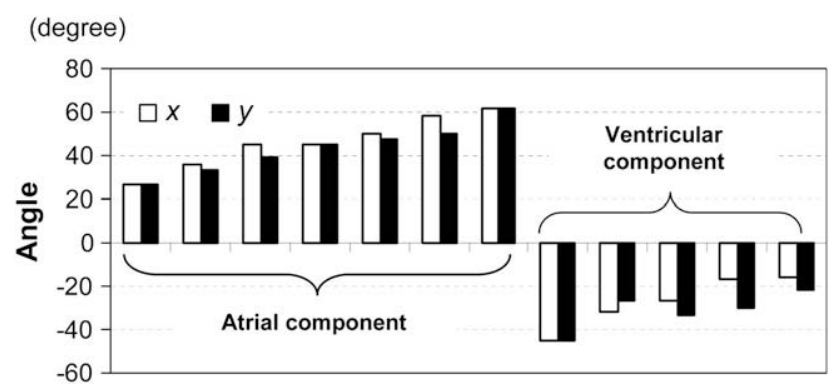

FIGURE 5. Angles of the bridging leaflets in relation to the atrioventricular junction.

greater than $80 \%$. They also had much larger ratios of minimal length/outlet length, suggesting a very small ventricular component in this entity. This finding was confirmed in another way by the direct measurement of the ventricular defect size. Scoop ratios in hearts with only a ventricular component yielded the smallest values, whereas those with both atrial and ventricular components showed the largest scoops despite considerable crossover with hearts that had only an atrial component. This scoop ratio indicates the extensiveness of a ventricular component in the direction of the apex. Not surprisingly, a ventricular component of the septal defect can extend not only toward the apex but also toward the outflow tract of the left ventricle. Such superior extension was not found in hearts with only a ventricular or only an atrial component, whereas it was frequently $(50 \%)$ found in hearts with both components. Inasmuch as a ventricular component is minimal in hearts with only a ventricular component as described above, it is little wonder that the ventricular component cannot extend superiorly either. Similarly, counter-scoop ratios were also minimal in hearts with only a ventricular component, whereas other types had much larger ratios. This minimal counter-scoop might explain why in these hearts both bridging leaflets of the atrioventricular valve can be attached to the underside of the atrial septum, thus eliminating an ostium primum defect. The atrioventricular junction ratios, which represent the degree of a gap between anterior and posterior atrioventricular junctions, were clearly different among the three subgroups. Hearts with only a ventricular component had the smallest values, whereas those with both components had the largest. In a normal heart, this gap is absent, forming the characteristic figure-of- 8 configuration of the left and right atrioventricular junctions. The more severe the atrioventricular malformation during the development of the heart, the larger the gap, with the aorta being more unwedged, leading to an elongated outlet length. ${ }^{1,13}$ This anatomic consequence is demonstrated well by the linear correlation between atrioventricular junction length and outlet length (Figure 3). The elongated outlet tract, as well as adherence of the superior bridging leaflet on the ventricular crest seen in partial AVSD, is thought to be a potential anatomic boundary for the development of obstruction in the left ventricular outflow tract. ${ }^{15-17}$ Considering the minimal inlet-outlet disproportion and the relationship of the superior bridging leaflet with the septal structure in hearts with only a ventricular component, one can reasonably assume that these hearts are least prone to the development of left ventricular outflow obstruction. Nonetheless, clinical implications of the above findings and their surgical relevance still need to be evaluated.

In contrast to the marked differences in the degree of ventricular deformity, hearts with only a ventricular component still possess the characteristic 5-leaflet configuration of the atrioventricular valve. The proportions of mural leaflets in the left atrioventricular valve orifice were similar to those of other forms, all being around $30 \%$ without inclusion of the septal length and around 20\% with inclusion (Figure 4, Table E2). These values were quite compatible with those of a previous study. ${ }^{2}$ Interestingly, these proportions were quite similar to those of its counterpart of the right-sided atrioventricular valve, again all being around $30 \%$ without inclusion of the septal length and around $20 \%$ with inclusion (Figure 4, Table E2). The proportions of the right mural leaflet seemed relatively constant irrespective of either intracardiac shunting level or the size of other leaflets of the right-sided valve. This consistency might support the assumption that as the superior bridging leaflet extends further into the right ventricle, there is concomitant diminution in size of the anterosuperior leaflet. ${ }^{1}$ On the other hand, axes of the bridging leaflets were clearly different between hearts with only a ventricular and only an atrial component. As expected, in hearts with only a ventricular component, the axes always directed toward the atrial side, whereas those of hearts with only an atrial component were always toward the ventricular side, with these absolute values being smaller in the former group (Figures 1 and 5). If one regards these values as the degree of leaflet disproportion from the true atrioventricular junction to which the leaflets should have aligned, smaller values might be associated with better valvular competency. Although we do not know the valvular function of our specimens during life, all of the reported cases with only a ventricular component had no significant insufficiency of the left-sided valve that required surgical management. ${ }^{11,12}$ This might be explained by mild disproportions of the leaflet axes in this group.

If surgical intervention for the valve is required, its approach can be a matter of debate. The left-sided valve is usually accessible through a right atriotomy in typical AVSD repair owing to a widely deficient ostium primum defect. However, in hearts with only a ventricular component, this is not the case. The surgical options are, therefore, either to partially excise a primum atrial septum (the floor of the foramen ovale) so as to allow visualization of the valve as in normal repair or, alternatively, to make a left atriotomy. The primum septum may be excised safely without trauma 

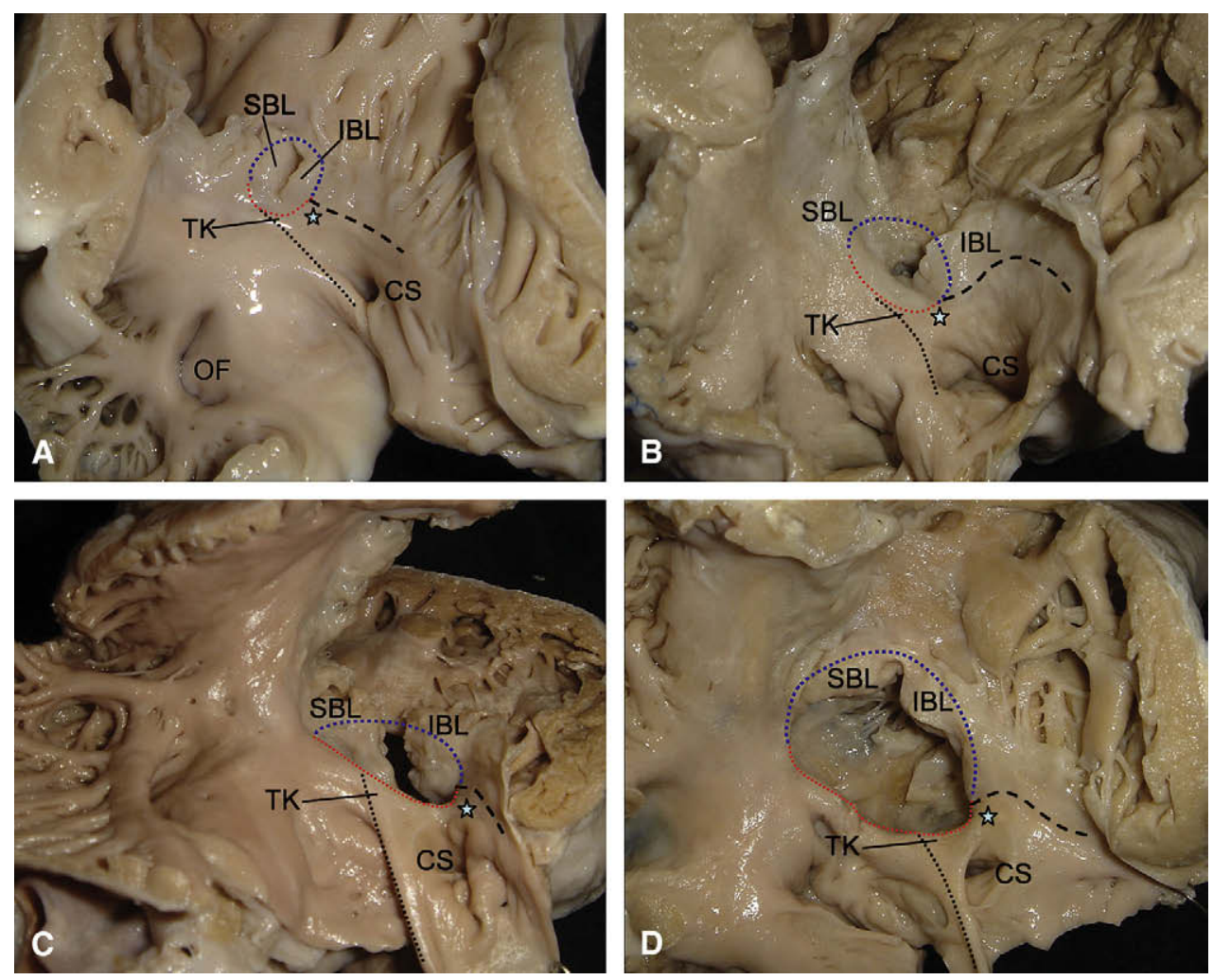

FIGURE 6. Photographs illustrating the Koch area of two hearts with atrioventricular septal defect with only a ventricular component (A and B), one heart with both atrial and ventricular components (C), and one heart with an atrial component only (D). The heart in part b has an enlarged coronary sinus owing to persistence of a left superior caval vein. The photographs were taken with the hearts positioned as they might be viewed by the surgeon at operation. The ventricular margin of the defect is indicated by the blue dotted line and the atrial margin is marked by the red dotted line. The black dotted line represents the tendon of Todaro and the broken line marks the posteroinferior hinge line (annulus) of the right atrioventricular valve. TK indicates the apex of the triangle of Koch. The connecting atrioventricular node (star) is displaced from $T K$ and anticipated to be located on the atrial side of the meeting point between the ventricular margin of the defect and the posteroinferior hinge line, which marks the atrioventricular junction. In hearts with only a ventricular component of the $\operatorname{defect}(\mathrm{A}$ and $\mathrm{B}$ ), owing to a shorter distance between the anterior and posterior margins of the defect, the atrioventricular node is likely to be located closer to the apex of the triangle of Koch than in the other forms (C and D). SBL, Superior bridging leaflet; $I B L$, inferior bridging leaflet; $T K$, apex of triangle of Koch; $C S$, coronary sinus; $O F$, oval fossa.

to the cardiac conduction system. Previous studies on the disposition of the atrioventricular node and conduction bundles have shown a posteroinferiorly displaced location at the juncture between the atrial and ventricular septa instead of at the apex of the triangle of Koch. ${ }^{18}$ However, these studies were not conducted on AVSDs with only a ventricular component. Our morphometric data show this subset to have the best formed atrioventricular junction with the smallest gap, suggesting the posteroinferior margin of the atrioventricular junction that bears the conduction tissues may be nearer the triangle of Koch than in the other subsets (Figure 6). Unfortunately, we could not make any histologic studies on our heart specimens to confirm this, inasmuch as we could not justify the destruction of such rare specimens, which are precious teaching materials. In the absence of hard evidence, it might be better to limit the excision of the septum primum to within the muscular rim of the fossa. Despite the lack of histologic evidence, it is still highly likely that this rare form of
AVSD possesses some degree of nodal displacement. Because of this, it is crucial, at least from a surgical point of view, to distinguish this group of hearts from other anomalies such as "inlet ventricular septal defect (VSD) with or without cleft mitral valve" or "canal type VSD," which do not have a common atrioventricular junction, bridging leaflets, or potential nodal displacement. In the past, numerous nomenclatures have been advocated to describe and classify hearts with interventricular shunting (this term does not necessarily indicate the presence of a VSD). Some authors have considered the rare hearts described here as a type of VSD. Examples of such terminologies include "inlet" VSD by Soto, Ceballos, and Kirklin ${ }^{19}$ and "atrioventricular canal type" VSD by Van Praagh, Geva, and Kreutzer. ${ }^{20}$ They included hearts with or without a common atrioventricular junction, although Van Praagh himself commented that this type of defect can be called AVSD if there is a common atrioventricular "canal" ("junction" in 
our case). ${ }^{20}$ To our minds, it would only engender confusion to separate this group of hearts from the whole spectrum of AVSD and to place it under the designation of VSD simply because it has only interventricular shunting.

The difference in leaflet axes between the so-called ostium primum form and the form with a ventricular component only may affect not only preoperative valvular competency but also the late development of valvular dysfunction even in perfectly repaired valves. Since the axes of the bridging leaflets cannot be modified with surgery, the arrangement of the bridging leaflets in relation to the atrioventricular junction would not necessarily be the same after repair between the two forms of AVSD; the leaflets with only an atrial component are displaced downwardly like tethering, whereas those with only a ventricular component are displaced upwardly like prolapsing. In hearts with only an atrial component, hemodynamic changes after surgical repair will increase the left ventricular size as a result of increased ventricular volume load. This geometric change of the ventricle might worsen the function of already tethered leaflets, inasmuch as ventricular dilatation is thought to worsen valvular tethering. ${ }^{21,22}$ On the contrary, in hearts with only a ventricular component, left ventricular size would decrease after repair because of the elimination of the interventricular shunting. This geometric change might also make the "prolapsing" of the leaflets worse. In both cases, ventricular geometric changes after repair could theoretically produce adverse effects on valvular competency of the inherently displaced leaflets. These phenomena might partially explain the development of valvular dysfunction long after successful repair. ${ }^{23}$

Limitations of our study include the small number of hearts with only a ventricular component, which precluded us from performing any statistical analysis. Accordingly, it remains unclear whether our findings in the present study regarding this subset could be reasonably extrapolated to all hearts with this particular anatomy. We hope our study will stimulate further studies on this entity.

\section{CONCLUSION}

Hearts with only a ventricular component in our series had the mildest deformity of the ventricular mass with the least extensive septal defect as compared with other forms of AVSD. These findings might suggest that this minor entity represents the mildest end of the whole spectrum of AVSD. Although a fundamental configuration of the atrioventricular valve was still preserved in these hearts, upward displacement of the bridging leaflets is unique to this group. Since this arrangement is not modifiable and could be aggravated further after surgery, it might play a certain role in the development of late valve insufficiency. Furthermore, the connecting atrioventricular node may not be as displaced as in the other groups.
We appreciate Ms Manveer Sroya and Ms Carina Lim for their technical and secretarial assistance.

\section{References}

1. Becker AE, Anderson RH. Atrioventricular septal defects: what's in a name? J Thorac Cardiovasc Surg. 1982;83:461-9.

2. Penkoske PA, Neches WH, Anderson RH, Zuberbuhler JR. Further observations on the morphology of atrioventricular septal defects. J Thorac Cardiovasc Surg. 1985;90:611-22. Erratum in: J Thorac Cardiovasc Surg. 1988;95:146.

3. Ebels T, Anderson RH, Devine WA, Debich DE, Penkoske PA, Zuberbuhler JR. Anomalies of the left atrioventricular valve and related ventricular septal morphology in atrioventricular septal defects. J Thorac Cardiovasc Surg. 1990;99: 299-307.

4. Van Mierop LH, Alley RD, Kausel HW, Stranahan A. The anatomy and embryology of endocardial cushion defects. J Thorac Cardiovasc Surg. 1962;43:71-83.

5. Van Mierop LHS. Pathology and pathogenesis of the common cardiac malformations. Cardiovasc Clin. 1970;2:27-59.

6. Smallhorn JF, Sutherland GR, Anderson RH, Macartney FJ. Cross-sectional echocardiographic assessment of conditions with atrioventricular valve leaflets attached to the atrial septum at the same level. Br Heart J. 1982;48:331-41.

7. Smallhorn JF, de Leval M, Stark J, Somerville J, Taylor JF, Anderson RH, et al. Isolated anterior mitral cleft. Two dimensional echocardiographic assessment and differentiation from "clefts" associated with atrioventricular septal defect. $\mathrm{Br}$ Heart J. 1982;48:109-16.

8. Sigfusson G, Ettedgui JA, Silverman NH, Anderson RH. Is a cleft in the anterior leaflet of an otherwise normal mitral valve an atrioventricular canal malformation? J Am Coll Cardiol. 1995;26:508-15.

9. Kohl T, Silverman NH. Comparison of cleft and papillary muscle position in cleft mitral valve and atrioventricular septal defect. Am J Cardiol. 1996;77:164-9.

10. Sulafa AK, Tamimi O, Najm HK, Godman MJ. Echocardiographic differentiation of atrioventricular septal defects from inlet ventricular septal defects and mitral valve clefts. Am J Cardiol. 2005;95:607-10.

11. LaCorte MA, Cooper RS, Kauffman SL, Schiller MS, Golinko RJ, Griepp RB. Atrioventricular canal ventricular septal defect with cleft mitral valve. Angiographic and echocardiographic features. Pediatr Cardiol. 1982;2:289-95.

12. Virdi IS, Keeton BR, Shore DF. Atrioventricular septal defect with a well developed primary component of the atrial septum ("septum primum"). Int J Cardiol. 1985;9:243-7.

13. Ho SY, Rigby ML, Anderson RH. Atrioventircular septal defects. In: Ho SY, Rigby ML, Anderson RH, eds. Echocardiography in congenital heart disease made simple. London: Imperial College Press; 2005. p. 76-86.

14. Ebels T, Anderson RH. The concept and definition of an "intermediate form" of atrioventricular septal defect. J Thorac Cardiovasc Surg. 1991;102:799-800.

15. Piccoli GP, Ho SY, Wilkinson JL, Macartney FJ, Gerlis LM, Anderson RH. Leftsided obstructive lesions in atrioventricular septal defects: an anatomic study. J Thorac Cardiovasc Surg. 1982;83:453-60.

16. Ebels T, Ho SY, Anderson RH, Meijboom EJ, Eijgelaar A. The surgical anatomy of the left ventricular outflow tract in atrioventricular septal defect. Ann Thorac Surg. 1986;41:483-8.

17. Silverman NH, Gerlis LM, Ho SY, Anderson RH. Fibrous obstruction within the left ventricular outflow tract associated with ventricular septal defect: a pathologic study. J Am Coll Cardiol. 1995;25:475-81.

18. Thiene G, Wenink AC, Frescura C, Wilkinson JL, Gallucci V, Ho SY, et al. Surgical anatomy and pathology of the conduction tissues in atrioventricular defects. J Thorac Cardiovasc Surg. 1981;82:928-37.

19. Soto B, Ceballos R, Kirklin JW. Ventricular septal defects: a surgical viewpoint. J Am Coll Cardiol. 1989;14:1291-7.

20. Van Praagh R, Geva T, Kreutzer J. Ventricular septal defects: how shall we describe, name and classify them? J Am Coll Cardiol. 1989;14:1298-9.

21. Liel-Cohen N, Guerrero JL, Otsuji Y, Handschumacher MD, Rudski LG, Hunziker PR, et al. Design of a new surgical approach for ventricular remodeling to relieve ischemic mitral regurgitation: insights from 3-dimensional echocardiography. Circulation. 2000;101:2756-63.

22. Messas E, Pouzet B, Touchot B, Guerrero JL, Vlahakes GJ, Desnos M, et al. Efficacy of chordal cutting to relieve chronic persistent ischemic mitral regurgitation. Circulation. 2003;108(Suppl 1):II111-5.

23. Kanani M, Elliott M, Cook A, Juraszek A, Devine W, Anderson RH. Late incompetence of the left atrioventricular valve after repair of atrioventricular septal defects: the morphologic perspective. J Thorac Cardiovasc Surg. 2006;132:640-6, 646.e1-3. 
TABLE E1. Measurements on the septal surface and atrioventricar septal defect in three group of heast

\begin{tabular}{|c|c|c|c|}
\hline Shunting level & Only atrium & Only ventricle & $\begin{array}{l}\text { Both atrium } \\
\text { and ventricle }\end{array}$ \\
\hline No. examined (\%) & $12(71 \%)$ & $4(80 \%)$ & $39(70 \%)$ \\
\hline \multicolumn{4}{|c|}{ Length of the septal surface } \\
\hline Inlet ratio & $81 \%(67 \%-93 \%)$ & $93 \%(86 \%-96 \%)$ & $77 \%(60 \%-88 \%)$ \\
\hline Minimal ratio & $69 \%(50 \%-78 \%)$ & $79 \%(77 \%-86 \%)$ & $60 \%(48 \%-71 \%)$ \\
\hline No. examined (\%) & $12(71 \%)$ & $4(80 \%)$ & $37(66 \%)$ \\
\hline \multicolumn{4}{|l|}{ Length of the AVSD } \\
\hline Scoop ratio & $31 \%(19 \%-47 \%)$ & $15 \%(13 \%-23 \%)$ & $21 \%(16 \%-35 \%)$ \\
\hline Counter-scoop ratio & $17 \%(7 \%-39 \%)$ & $6 \%(4 \%-7 \%)$ & $18 \%(12 \%-32 \%)$ \\
\hline AV junction ratio & $41 \%(24 \%-52 \%)$ & $22 \%(16 \%-33 \%)$ & $48 \%(23 \%-79 \%)$ \\
\hline
\end{tabular}


TABLE E2. Circumferential attachments of value leaflets and angles of bridging leaflets.

\begin{tabular}{|c|c|c|c|}
\hline Shunting level & $\begin{array}{c}\text { Only atrium } \\
(\mathbf{n}=17)\end{array}$ & $\begin{array}{l}\text { Only ventricle } \\
\quad(\mathbf{n}=\mathbf{5})\end{array}$ & $\begin{array}{l}\text { Both atrium and ventricle } \\
\qquad(\mathrm{n}=\mathbf{5 6})\end{array}$ \\
\hline No. examined $(\%)$ & $7(41 \%)$ & $4(80 \%)$ & $36(64 \%)$ \\
\hline \multicolumn{4}{|l|}{ Left AV valve } \\
\hline $\mathrm{LM} /(\mathrm{LM}+\mathrm{LSB}+\mathrm{LIB})$ & $32 \%(23 \%-38 \%)$ & $34 \%(32 \%-36 \%)$ & $32 \%(24 \%-44 \%)$ \\
\hline $\mathrm{LM} /(\mathrm{LM}+\mathrm{LSB}+\mathrm{LIB}+\mathrm{Sep})$ & $20 \%(17 \%-27 \%)$ & $27 \%(24 \%-32 \%)$ & $22 \%(17 \%-31 \%)$ \\
\hline \multicolumn{4}{|l|}{ Right AV valve } \\
\hline RM/(RSB+AS+RM+RIB) & $28 \%(21 \%-35 \%)$ & $29 \%(24 \%-37 \%)$ & $30 \%(15 \%-45 \%)$ \\
\hline $\mathrm{RM} /(\mathrm{RSB}+\mathrm{AS}+\mathrm{RM}+\mathrm{RIB}+\mathrm{Sep})$ & $21 \%(15 \%-24 \%)$ & $25 \%(18 \%-33 \%)$ & $19 \%(11 \%-31 \%)$ \\
\hline $\mathrm{AS} /(\mathrm{RSB}+\mathrm{AS}+\mathrm{RM}+\mathrm{RIB})$ & $35 \%(21 \%-59 \%)$ & $13 \%(10 \%-26 \%)$ & $28 \%(9 \%-52 \%)$ \\
\hline $\mathrm{AS} /(\mathrm{RSB}+\mathrm{AS}+\mathrm{RM}+\mathrm{RIB}+\mathrm{Sep})$ & $35 \%(21 \%-59 \%)$ & $11 \%(9 \%-20 \%)$ & $19 \%(6 \%-40 \%)$ \\
\hline $\mathrm{RSB} /(\mathrm{RSB}+\mathrm{AS}+\mathrm{RM}+\mathrm{RIB})$ & $13 \%(7 \%-21 \%)$ & $30 \%(14 \%-31 \%)$ & $17 \%(6 \%-40 \%)$ \\
\hline $\mathrm{RSB} /(\mathrm{RSB}+\mathrm{AS}+\mathrm{RM}+\mathrm{RIB}+\mathrm{Sep})$ & $10 \%(5 \%-15 \%)$ & $23 \%(13 \%-27 \%)$ & $11 \%(4 \%-27 \%)$ \\
\hline$(\mathrm{RSB}+\mathrm{AS}) /(\mathrm{RSB}+\mathrm{AS}+\mathrm{RM}+\mathrm{RIB})$ & $48 \%(35 \%-66 \%)$ & $42 \%(27 \%-57 \%)$ & $48 \%(35 \%-60 \%)$ \\
\hline$(\mathrm{RSB}+\mathrm{AS}) /(\mathrm{RSB}+\mathrm{AS}+\mathrm{RM}+\mathrm{RIB}+\mathrm{Sep})$ & $34 \%(25 \%-45 \%)$ & $36 \%(24 \%-43 \%)$ & $32 \%(23 \%-45 \%)$ \\
\hline No. examined $(\%)$ & $7(41 \%)$ & $5(100 \%)$ & \\
\hline \multicolumn{4}{|l|}{ Angle of the bridging leaflets } \\
\hline Superior bridging leaflet & $45^{\circ}\left(27^{\circ}-62^{\circ}\right)$ & $-27^{\circ}\left(-45\right.$ to $\left.-16^{\circ}\right)$ & \\
\hline Inferior bridging leaflet & $45^{\circ}\left(27^{\circ}-62^{\circ}\right)$ & $-34^{\circ}\left(-45^{\circ}\right.$ to $\left.-22^{\circ}\right)$ & \\
\hline
\end{tabular}

$A V$, Atrioventricular; $L M$, left mural leaflet; $L S B$, left superior bridging leaflet; $L I B$, left inferior bridging leaflet; Sep, septum; $R M$, right mural leaflet; $R S B$, right superior bridging leaflet; $A S$, anterosuperior leaflet; $R I B$, right inferior bridging leaflet. 